Quim. Nova, Vol. 29, No. 2, 368-372, 2006

\title{
OTIMIZAÇÃO DO PROCESSO DE EXTRAÇÃO E ISOLAMENTO DO ANTIMALÁRICO ARTEMISININA A PARTIR DE Artemisia annua L.
}

\author{
Rodney Alexandre Ferreira Rodrigues*, Mary Ann Foglio, Sinésio Boaventura Júnior, Adriana da Silva Santos e \\ Vera Lúcia Garcia Rehder \\ Centro Pluridisciplinar de Pesquisas Químicas, Biológicas e Agrícolas, Universidade Estadual de Campinas, \\ CP 6171, 13081-970 Campinas - SP
}

Recebido em 30/9/04; aceito em 27/7/05; publicado na web em 20/1/06

\begin{abstract}
OPTIMIZATION OF THE EXTRACTION AND ISOLATION OF THE ANTIMALARIAL DRUG ARTEMISININ FROM Artemisia аппиа L.. Malaria is still one of the major diseases in the world, causing physical and economic problems in tropical regions. Artemisinin (Qinghaosu), a natural compound identified in Artemisia аппиа L., is an effective drug mainly against cerebral malaria. The action of this drug is immediate and parasitaemia in the treatment of drug-resistant malaria is rapidily reduced, justifying the industrial production of artemisinin. This article focuses on the industrial production of this potent antimalarial drug, including strategies for enhancing yield using inexpensive and easy steps.
\end{abstract}

Keywords: malaria; artemisinin production; Artemisia аппиа $\mathrm{L}$.

\section{INTRODUÇÃO}

A ocorrência mundial de casos de malária nos últimos anos atingiu cerca de 300 a 500 milhões de casos, dos quais 1 a 3 milhões foram acometidos por morte ${ }^{1}$.

Esses números assustadores têm impulsionado a pesquisa em vários campos, incluindo a obtenção de novos compostos com atividade antimalárica, bem como tentativas no intuito de obter vacinas para cura da doença e até o sequenciamento genético do Plasmodium spp. Várias instituições mundiais têm tentado o sequenciamento genético do parasita, algumas em fase de estudo e outras com o sequenciamento já completo. As espécies estudadas incluem Plasmodium falciparum, P. yoelii, P. chabaudi, P. berghei, P. knoulesi e $P$. vivax ${ }^{1}$.

A tentativa em obter resultados promissores com o uso de vacinas tem sido objeto de estudos desde a década de 50. Atualmente já existem vacinas para combate ao $P$. falciparum e ao $P$. vivax ${ }^{2}$, mas ainda são necessários esforços no sentido de obter vacinas capazes de combater outras espécies como o P. malariae e P. ovale. A vacina pode ser uma ferramenta útil, porém parasitas como o $P$. falciparum são desafiadores pois se tratam de espécies causadores da doença de forma severa e variada ${ }^{3}$.

O principal parasita causador desta doença, o Plasmodium falciparum, tem desenvolvido resistência a agentes quimioterápicos sintéticos como cloroquina, mefloquina, halofantrina (Figura 1) e sulfadoxina, dificultando o tratamento da doença através de seu uso. A resistência a compostos antimaláricos, como cloroquina e sulfadoxina, já atinge áreas enormes, incluindo continentes como a América do Sul (Amazônia e norte do continente), África (parte central do continente ou sub Saara) e Ásia (principalmente Índia).

A resistência é um fator importante a ser considerado, porém a segurança e o custo também limitam o uso destes compostos. Aliado a isto, está o fato de que o vetor da malária, o mosquito Anopheles $s p$, abundante em regiões tropicais, tornou-se resistente a inseticidas. Na década de 50, houve um controle da doença e da

*e-mail: rodney@cpqba.unicamp.br

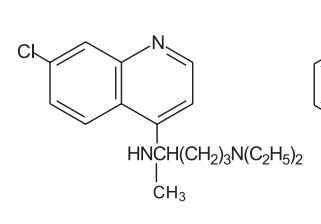

(1)

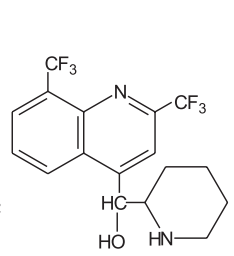

(2)

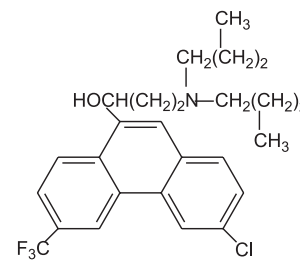

(3)
Figura 1. Estruturas químicas da cloroquina (1), mefloquina (2) e halofantrina (3)

disseminação do mosquito com quase erradicação da mesma, pois ainda não havia resistência aos inseticidas e o custo dos compostos antimaláricos era menor. Na década de 60 , houve um reaparecimento da doença de forma mais severa e preocupante pois passou a apresentar resistência ao DDT, atingindo patamares cada vez maiores de casos, principalmente em crianças ${ }^{4-8}$.

Pesquisadores chineses estudaram mais de trinta espécies do gênero Artemisia pesquisando uma possível atividade antimalárica, porém, só Artemisia annua L. e Artemisia apiacea Hance provaram ser eficazes contra Plasmodium falciparum e Plasmodium vivax. A busca por novos compostos antimaláricos incentivou o estudo de outras espécies de Artemisia, tais como Artemisia ludovica, A. vulgaris, A. schmidtiana, A. pontica, A. arbuscula e A. drancunculus, entretanto, nenhuma destas espécies apresentou atividade farmacológica ${ }^{9}$. As espécies $A$. апnиa L. e A. apiacea Hance apresentam um princípio ativo, denominado artemisinina, cuja estrutura é uma lactona sesquiterpênica com um grupo 1,2,4-trioxano (Figura 2), que foi identificada a partir de seu extrato etéreo e demonstrou atividade antimalárica durante testes farmacológicos. A demanda mundial pela artemisinina, no tratamento da malária, cresceu nas duas últimas décadas, devido a suas vantagens em relação a outros compostos antimaláricos. A artemisinina possui ação rápida atuando contra Plasmodium vivax e P. falciparum, inclusive sobre as formas de malária resistentes ao tratamento com cloroquinas e em casos de malária cerebral ${ }^{4,9-14}$. 


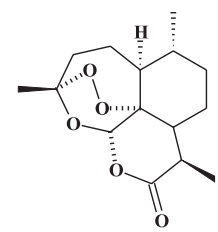

(4)

Figura 2. Estrutura química da artemisinina (4)

O mecanismo de ação, aspectos clínicos e toxicidade da artemisinina têm sido extensamente estudados nos últimos anos, assim como estudos agrotecnológicos, farmacológicos e químicos (elucidação estrutural) de outros compostos sesquiterpênicos presentes na planta ${ }^{6,11,15-20}$.

Este trabalho teve como objetivo a redução dos custos de produção de artemisinina através da otimização do método de extração e purificação com o emprego de reagentes de menor custo, aliado a técnicas operacionais de execução rápida e simples.

\section{PARTE EXPERIMENTAL}

Empregaram-se neste estudo folhas de um híbrido de Artemisia annua L. (Ch x Viet55) proveniente do campo experimental do CPQBA. O material vegetal usado foi seco em estufa com ventilação forçada a $45^{\circ} \mathrm{C}$ até peso constante e suas folhas após serem segregadas do caule, moídas em moinho de facas marca Primotécnica, que foram seqüencialmente extraídas com etanol $96^{\circ}$ GL.

Foram avaliados dois métodos de extração, denominados processo clássico e processo de extração em série, empregando-se 1 $\mathrm{kg}$ de planta seca/moída para o processo de extração clássico e 10 $\mathrm{kg}$ de planta seca/moída para o processo de extração em série, com o objetivo de minimizar o consumo do líquido extrator. Estes processos estão descritos a seguir:

\section{Processo clássico de extração}

Neste processo a planta foi extraída empregando-se etanol $96^{\circ}$ GL como líquido extrator, realizado com auxílio de agitação mecânica, durante $4 \frac{1}{2} \mathrm{~h}\left(3 \mathrm{x}\right.$ de $1 \frac{1}{2} \mathrm{~h}$ h) à temperatura ambiente. Os extratos obtidos foram filtrados, reunidos e concentrados até $1 / 3$ do volume total, fornecendo um extrato denominado extrato bruto concentrado. $\mathrm{O}$ extrato bruto evaporado até a secura foi processado conforme descrito na etapa de purificação e isolamento.

O processo clássico foi testado com planta seca/moída e seu fluxograma está ilustrado na Figura 3.

\section{Processo de extração em série}

Este processo baseou-se na utilização de dois tanques extratores em série, onde o primeiro tanque foi alimentado com a planta seca/ moída e $40 \%$ do volume total de etanol $96^{\circ}$ GL. A agitação, o tempo de extração e a temperatura foram os mesmos utilizados no processo clássico de extração. $\mathrm{O}$ extrato resultante no primeiro tanque foi filtrado e transferido para o segundo, para ser utilizado como líquido extrator de uma porção nova de planta seca/moída, enquanto o primeiro tanque era alimentado com novo líquido extrator (30\% do volume total). A operação foi realizada por 3 vezes, totalizando 3 extratos que passaram consecutivamente no primeiro e no segundo tanques e que foram reunidos para posterior evaporação. $\mathrm{O}$ fluxograma deste processo está ilustrado na Figura 4.

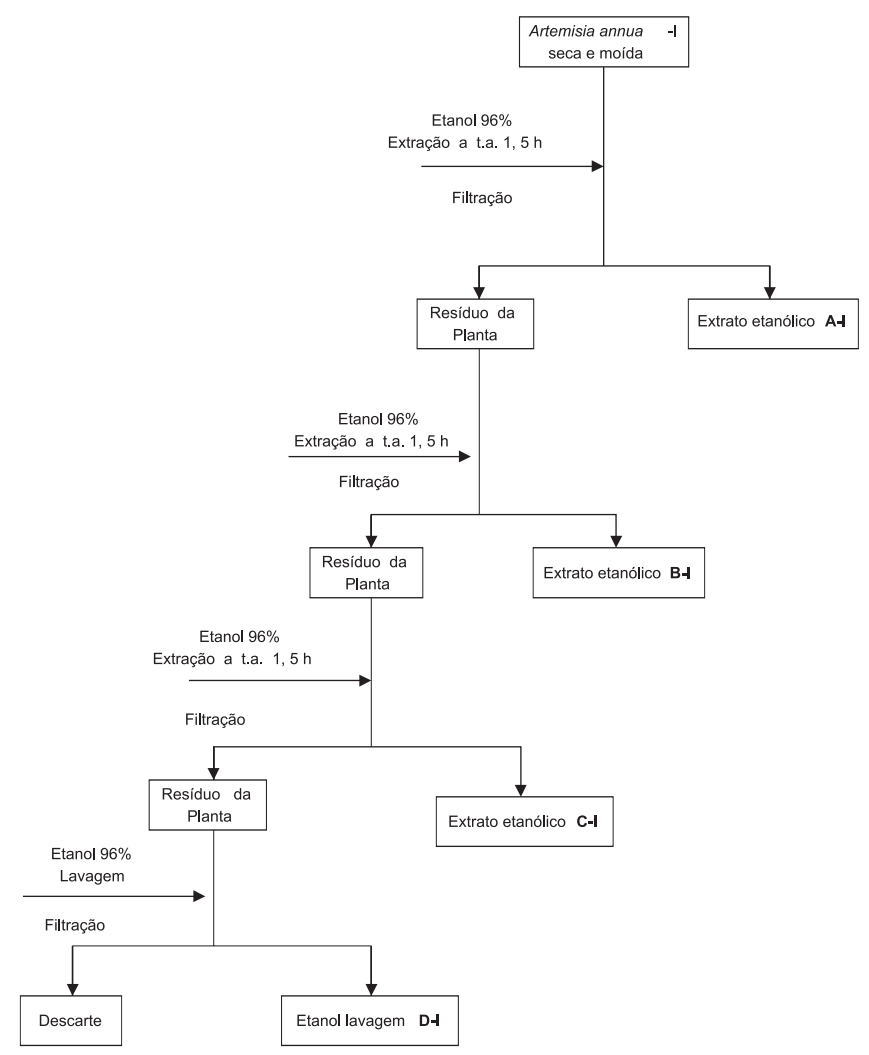

Figura 3. Fluxograma do processo clássico de extração da artemisinina a partir da A. annua $L$.

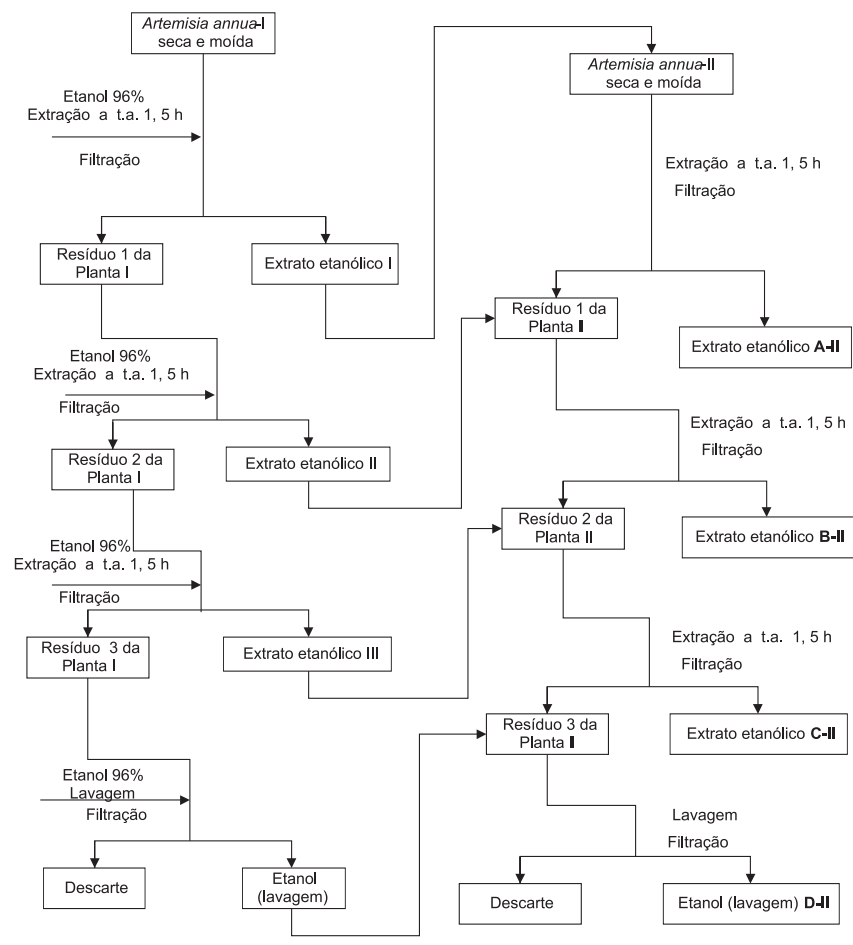

Figura 4. Fluxograma do processo de extração em série da artemisinina a partir da A. annua $L$.

Esta operação em série permitiu a redução do volume de solvente empregado no processo clássico para menos da metade, o que representa um fator determinante no custo de produção em um processo em grande escala. 
Etapa de purificação e isolamento - comum aos processos de extração clássico e em série

Após a exaustão da planta com etanol, os extratos foram reunidos, concentrados até $30 \%$ do volume inicial e tratados com carvão ativo Carbomafra (Curitiba, Brasil), durante 1 1/2 h sob agitação mecânica, à temperatura ambiente. $\mathrm{O}$ carvão foi eliminado através de filtração à vácuo em funil de Büchner, com auxílio de uma pré capa de terra diatomácea (Celite). Obteve-se uma solução de coloração amarelo escuro, que foi evaporada até a secura para determinação do rendimento extrativo. Ao extrato seco adicionou-se etanol e dióxido de silício industrial marca Zeosil 175, Rhodia (Paulínia, Brasil), na proporção de 1:1 (extrato seco:Zeosil). A sílica e o extrato foram para um misturador marca Munson (Nova Iorque, Estados Unidos) e seqüencialmente eliminou-se o etanol por destilação sob vácuo, em rotaevaporador marca Büchi modelo R-151 (Flawil, Suíça). A mistura foi adicionada ao topo de uma coluna de aço inox, previamente empacotada com a mesma fase estacionária, para separação cromatográfica do tipo filtração em coluna sob vácuo.

A fração enriquecida foi tratada com carvão ativo durante $1 / 2 \mathrm{~h}$ à temperatura ambiente sob agitação, e em seguida filtrada sob vácuo. Obteve-se uma solução levemente amarelada, que foi evaporada até se obter $5 \%$ do volume inicial e resfriada a $5{ }^{\circ} \mathrm{C}$ por $2 \mathrm{~h}$ para cristalização do princípio ativo. Os cristais foram filtrados em papel de filtro, em um funil de Büchner, sob vácuo, e lavados com uma mistura de hexano/acetato de etila $\left(85 / 15\right.$, v/v) previamente resfriada a $5{ }^{\circ} \mathrm{C}$.

As etapas de extração, purificação e isolamento da artemisinina estão ilustradas na Figura 5 e os equipamentos empregados, na Figura 6.

\section{RESULTADOS E DISCUSSÃO}

A Artemisia annua L. utilizada neste estudo apresentou teor de artemisinina de $1,2 \%(\mathrm{~m} / \mathrm{m})$ determinado por $\mathrm{CLAE}^{21}$ e $9 \%$ de umidade determinada por perda por dessecação em estufa ${ }^{22}$.

A segregação das folhas na etapa de moagem foi importante, haja vista que o caule não contém artemisinina e também para se evitar excesso de compostos graxos oriundos do caule, que dificultariam a purificação seqüencial através da cromatografia em coluna ${ }^{23}$.

Com relação ao custo, houve preocupação em sua redução nas etapas de extração e de cromatografia em coluna. Algumas técnicas de extração e purificação, descritas em literatura, são bastante simples ${ }^{24-26}$, porém, utilizam solventes caros, como acetonitrila, ou agressivos ao meio ambiente, como diclorometano.

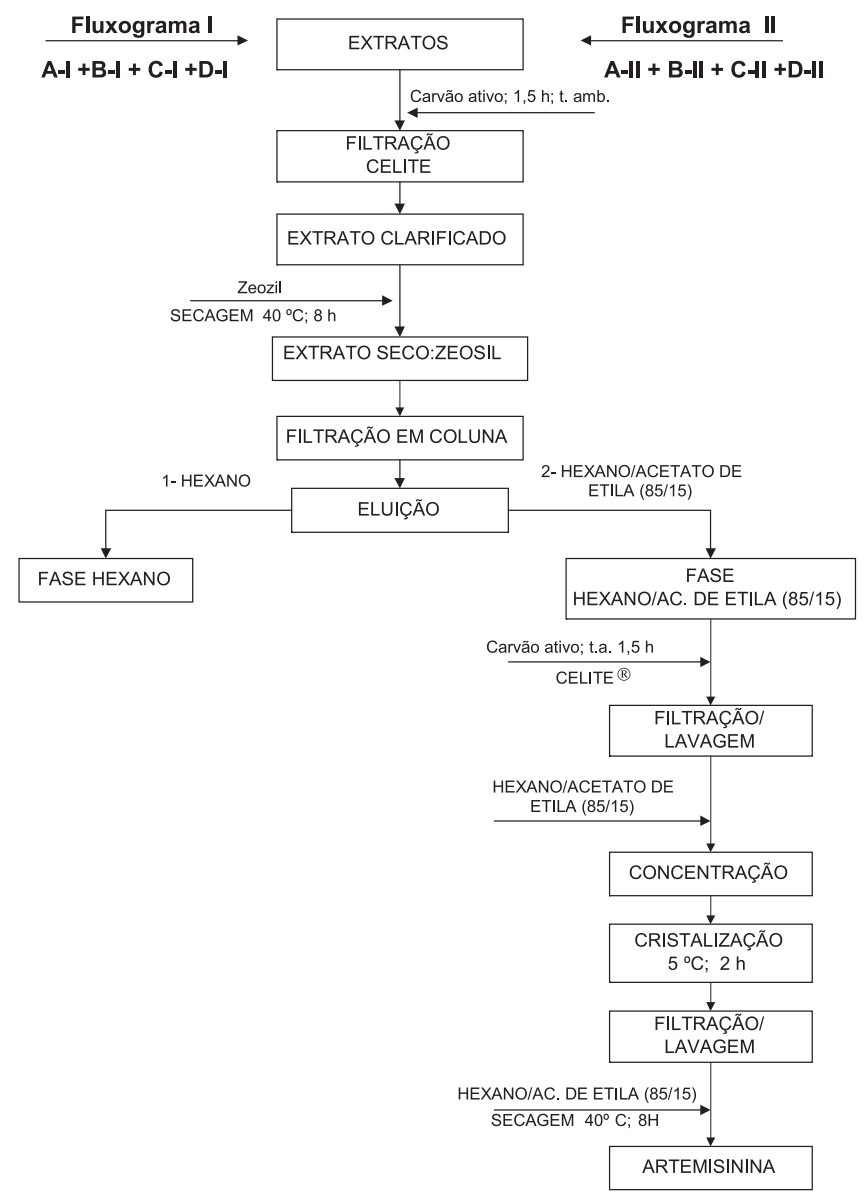

Figura 5. Fluxograma do processo de purificação e isolamento da artemisinina

Para se determinar o melhor solvente extrator, foram testados os seguintes solventes: tolueno, diclorometano, tetracloroetileno, metanol, hexano e etanol. Levando-se em conta os aspectos de segurança, eficiência extrativa, toxicidade, agressão ao meio ambiente e seletividade, constatou-se que o poder extrativo variava muito pouco de um solvente para outro ${ }^{23}$.

O hexano empregado para extração de artemisinina eleva em muito o conteúdo de impurezas apolares, apesar disto seu emprego é citado na literatura ${ }^{27}$. A opção de escolha recaiu sobre o etanol, que revelou ter um poder extrativo comparável aos demais, porém

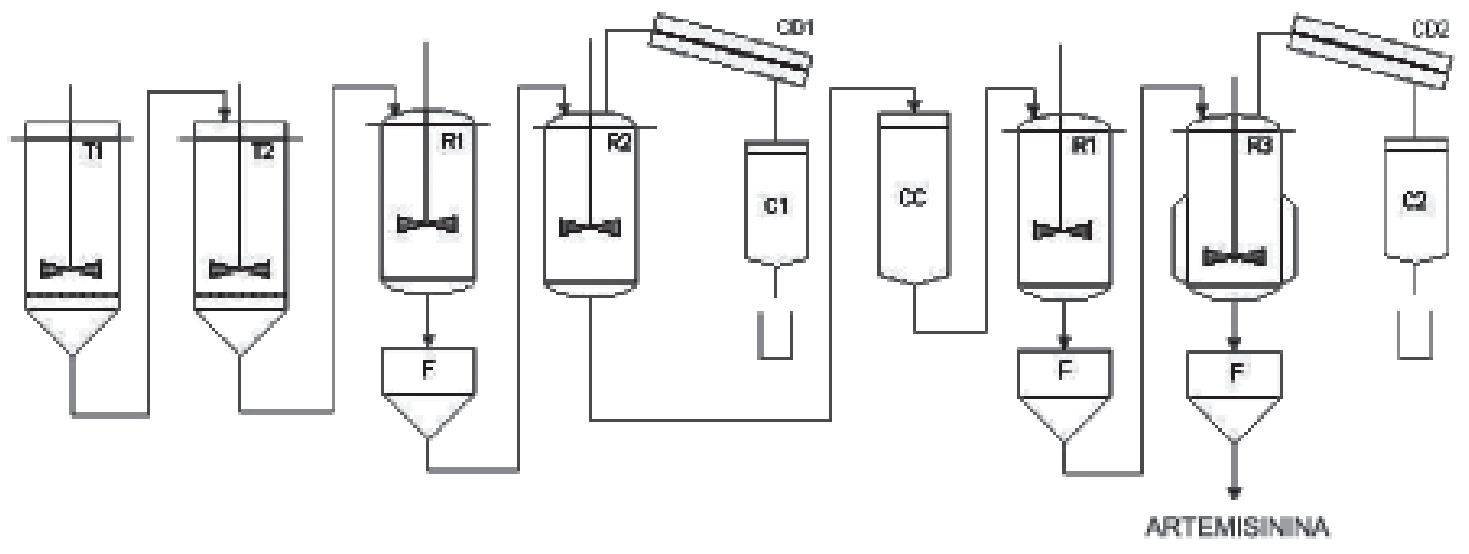

Figura 6. CC: Coluna cromatográfica em aço inox; C1/C2: Vaso coletor; CD1/CD2: Condensador; F: Filtro à vácuo; R1: Reator em aço inox com agitação mecânica; R2: Reator em aço inox para destilação de solvente e preparação da mistura extrato seco: Zeosil; R3: Reator em aço inox encamisado, para resfriamento; T1/T2: Tanque em aço inox com agitação mecânica e filtro interno 
Tabela 1. Quantidades de reagentes empregados nos processos de extração clássico e em série, para obtenção de artemisinina a partir de folhas de A. annua seca e moída

\begin{tabular}{lcccc}
\hline Etapa & \multicolumn{2}{c}{ Processo Clássico } & \multicolumn{2}{c}{ Processo em série } \\
& Massa $(\mathrm{kg})$ & Volume $(\mathrm{L})$ & Massa $(\mathrm{kg})$ & 1,0 \\
Folhas de A. annua $\mathrm{L}$. & 1,0 & - & 5,0 & - \\
Etanol 96 ${ }^{\circ} \mathrm{GL}$ (extração) & 14,19 & 17,52 & 0,8 & 6,3 \\
Etanol (lavagem planta) & 0,8 & 1,0 & 2,29 & 1,0 \\
Extrato p/ clarificação & 3,66 & - & $0,07 / 0,05$ & - \\
Carvão ativo/Celite & $0,07 / 0,10$ & - & 0,24 & - \\
Etanol (lavagem carvão) & 0,43 & 0,53 & 0,3 \\
\hline
\end{tabular}

com menor toxicidade e custo, confirmando resultados prévios de literatura ${ }^{28}$.

Também foi testada a influência da granulometria do pó obtido na etapa de moagem e a composição das fases móvel e estacionária empregadas na separação cromatográfica. O emprego da tradicional sílica gel para purificação dos extratos, tornou-se incompatível pelo custo, uma vez que a escala pretendida foi a industrial. Uma solução bastante compatível com o propósito deste trabalho foi a aplicação do Zeosil em substituição à sílica gel tradicional.

As quantidades de solvente e reagentes empregados nos processos de extração clássico e em série, os valores comparativos referente ao custo de produção final da artemisinina, estão descritos na Tabelas 1 e as quantidades de materiais utilizados no isolamento e na purificação deste princípio ativo estão descritas na Tabela 2.

Tabela 2. Quantidades de materiais utilizados no isolamento e purificação da artemisinina

\begin{tabular}{lll}
\hline Etapa & Clássico & Em série \\
\hline Zeosil para topo da coluna & $27 \mathrm{~g}$ & $27 \mathrm{~g}$ \\
Zeosil para empacotamento & $178 \mathrm{~g}$ & $100 \mathrm{~g}$ \\
$\begin{array}{l}\text { Hexano:Hexano/acetato de etila }(85 / 15) \\
\text { Hexano/acetato de etila (85/15) }\end{array}$ & $3,7 / 4,8 \mathrm{~L}$ & $0,84 / 2,0 \mathrm{~L}$ \\
$\begin{array}{l}\text { (lavagem coluna) } \\
\text { Carvão ativo/Celite }\end{array}$ & $0,30 \mathrm{~L}$ & $0,25 \mathrm{~L}$ \\
$\begin{array}{l}\text { Hexano/acetato de etila } \\
\text { (lavagem na cristalização) }\end{array}$ & $64 \mathrm{~g} / 90 \mathrm{~g}$ & $33 \mathrm{~g} / 33 \mathrm{~g}$ \\
\hline
\end{tabular}

Durante a etapa de cromatografia em coluna utilizou-se um gradiente de eluição que foi iniciado com hexano (100 volumes), que permitiu a separação da matéria graxa e demais constituintes apolares, possibilitando na seqüência o enriquecimento da artemisinina na fase móvel hexano/acetato de etila $(85 / 15$, v/v).

Nesta etapa, verificou-se dois fatores importantes para assegurar uma boa separação da artemisinina:razão (diâmetro da coluna/ altura de sílica) e vazão da eluição. O valores otimizados obtidos para estes dois parâmetros foram $1 \frac{1}{2}$ e $15 \mathrm{~mL} / \mathrm{min}$, respectivamente. Desta maneira foi possível, através de uma coluna cromatográfica de baixo custo e rápida execução, o fracionamento da artemisinina do extrato bruto tratado com carvão ativo.

O monitoramento do teor de artemisinina durante o decorrer dos processos foi realizado por fotodensitometria/cromatografia em camada delgada, uma metodologia semi-quantitativa, rápida, de baixo custo e que demonstrou ser bastante útil no monitoramento das etapas ${ }^{29}$.

A pureza da artemisinina foi determinada por CLAE, através do doseamento obtido com o uso de um padrão analítico primário, segundo metodologia descrita por Ferreira e colaboradores ${ }^{21}$. Obteve-se para os processos de extração clássico e em série um teor de artemisinina de 91,0 e $91,3 \%$, respectivamente. O ponto de fusão dos sólidos obtidos foi de 151-153,7 e 150,9-153,5 ${ }^{\circ} \mathrm{C}$, para os processos de extração clássico e em série, respectivamente, justificando uma recristalização do sólido obtido, uma vez que se obteve um teor baixo e os pontos de fusão ficaram abaixo do valor citado em literatura, de $154,0{ }^{\circ} \mathrm{C}^{30}$ e $156-157{ }^{\circ} \mathrm{C}^{31}$. Os sólidos obtidos apresentaram coloração branca e o rendimento global dos processos ficou em torno de $73 \%$, sendo de 2 a 16,5 vezes maior que os valores encontrados em literatura ${ }^{26,27,32}$.

\section{CONCLUSÕES}

O emprego da técnica extrativa em série possibilitou uma redução de $65 \%$ no consumo de solvente, com economia de 2,5 vezes. Além disto, a utilização do etanol nesta etapa possibilitou um processamento mais seguro, em razão da menor toxicidade deste solvente em relação a outros solventes. Outra razão para esta escolha foi o fato do etanol ser largamente produzido no país, permitindo rápida aquisição a preços acessíveis.

Na etapa de purificação, o processo possibilitou uma redução de solventes, representando uma economia de cerca de 2,7 vezes.

A utilização da técnica cromatográfica de filtração à vácuo permitiu rapidez nesta etapa, e a aplicação do Zeosil como fase estacionária possibilitou economia de 65 vezes em relação à sílica tradicional.

A clarificação dos extratos com carvão ativo possibilitou uma coluna cromatográfica com economia de eluentes e a cristalização direta da artemisinina a partir da fração hexano/acetato de etila $(85 / 15, \mathrm{v} / \mathrm{v})$,

Na moagem, a granulometria de malha ideal foi $\leq 1 \mathrm{~mm}$.

Os resultados obtidos pela extração em série indicam a viabilidade de produção de artemisinina a um custo global de 2,6 vezes o custo do processo clássico.

Este estudo envolveu o emprego de técnicas operacionais simples, reagentes e solventes baratos.

\section{AGRADECIMENTOS}

À FAPESP, FAEP, Fundação Banco do Brasil, CNPq-RHAE e Divisão de Agrotecnologia CPQBA-UNICAMP pelo fornecimento do material vegetal.

\section{REFERÊNCIAS}

1. Hoffman, S. L.; Subramanian, G. M.; Collins, F. H. ; Venter, J. C.; Nature 2002, 415, 702 .

2. Clide, D. F.; Bull. World Health Organ 1990, 68, 9

3. Richie, T. L.; Saul, A.; Nature 2002, 415, 694.

4. Ridley, R. G.; Nature 2002, 415, 686.

5. Rogers, D. J.; Randolph, S. E.; Snow, R. W.; Hay, S. I.; Nature 2002, 415, 710 
6. Agtmael, M. A.; Eggelte, T. A.; Boxtel, C. J.; TiPS 1999, 20, 199

7. Meshnick, S. R.; Thomas, A.; Ranz, A.; Xu, C. M.; Pan, H. Z.; Mol. Biochem. Parasitol. 1991, 49, 181.

8. Heyman, G.; Superinteressante 1991, $n^{\circ} 2,41$

9. Klayman, D. L.; Science 1985, 288, 1049.

10. Balint, G. A.; Pharmacol. Ther. 2001, 90, 261.

11. Meshnick, S. R.; Jefford, C. W.; Posner, G. H.; Avery, M. A., Peters, W.; Parasitol. Today 1996, 12, 79 .

12. Sharma, A.; Bindra, R. L.; Tewari, R.; Curr. Res. Med. Arom. Plants 1991, $13,46$.

13. Klayman, D. L.; Lin, A. J.; Acton, N.; Scovill, J. P.; Hoch, J. M.; Milhous, W. K.; Theoharides, A. D.; Dobek, A. S.; J. Nat. Prod. 1984, 47, 715.

14. China Cooperative Research Group On Qinghaosu And Its Derivatives As Antimalarials; J. Traditional Chinese Medicine 1982, 2, 2.

15. Foglio, M. A.; Dias, P. C.; Antônio, M. A.; Possenti, A.; Rodrigues, R. A. F.; Silva, E. F.; Rehder, V. L. G.; Carvalho, J. E.; Planta Med. 2002, 68, 515.

16. Cheng, F.; Shen, J.; Luo, X.; Zhu, W.; Gu, J.; Ji, R.; Jiang, H.; Chen, K.; Bioorg. Med. Chem. 2002, 10, 2883.

17. Mueller, M. S.; Karhagomba, I. B.; Hirt, H. M.; Wemakor, E.; J. Ethnopharmacology 2000, 73, 487.

18. Genovese, R. F.; Newman, D. B.; Brewer, T. G.; Pharmacol. Biochem. Behav. 2000, 67, 37.
19. Dhingra, V.; Vishweshwar, R.; Narasu, M. L.; Life Sci. 2000, 66, 279

20. Sy, L. K.; Brown, G. D.; Tetrahedron 1998, 54, 4345.

21. Ferreira, J. F. S.; Charles, D. J.; Wood, K.; Janick, J.; Simon, J. E.; Phytochem. Anal. 1994, 5, 116.

22. Farmacopéia Brasileira, $4^{\mathrm{a}}$ ed., Atheneu Ed.: São Paulo, 1988, parte I, cap. V.2.9.

23. Foglio, M. A.; Tese de Doutorado, Universidade Estadual de Campinas, Brasil, 1996.

24. Sy, L. K.; Brown, G. D.; Phytochemistry 2001, 58, 1159.

25. ElFeraly, F. S.; ElSohly, H. N.; US pat. 4,952,603 1990.

26. ElSohly, H. N.; Croom Jr, E. M.; ElFeraly, F. S.; ElSherei, M. M.; J. Nat. Prod. 1990, 53, 1560.

27. Roth, R. J.; Acton, N.; J. Chem. Educ. 1989, 66, 349

28. Rodrigues, R. A. F.; Relatório técnico, FAEP/Universidade Estadual de Campinas, Brasil, 1995.

29. Marchese, J. A.; Dissertação de Mestrado, Universidade Estadual de Campinas, Brasil, 1999

30. ElSohly, H. N.; Croom Jr, E. M.; ElSohly, M. A.; Pharm. Res. 1987, 4, 258.

31. Budavari, S., ed.; The Merck Index-11th.; Merck \& Co Inc.: Rahway, NJ, USA, 1989.

32. Chan, K. L.; Yuen, K. H.; Takayanagi, H.; Janadasa, S.; Peh, K. K.; Phytochemistry 1997, 7, 1209. 